\title{
Determinants of research productivity during postgraduate medical education: a structured review
}

\author{
Kevin B. Laupland ${ }^{1,2^{*}}$, Felicity Edwards ${ }^{2}$ and Jayesh Dhanani ${ }^{1,3}$
}

\begin{abstract}
Background: Although formal participation in research is an integral and often mandatory component of clinical training programs, resulting productivity is highly variable. The objective of this review was to identify determinants of successful research performance among graduate medical education trainees.

Methods: A structured review of the published literature was performed by searching PubMed, CINAHL, and EMBASE from inception through to 7 April, 2021. Articles examining graduate medical education trainee research productivity evidenced by publications in peer-reviewed journals were included.

Results: Eighty-five articles were included of which most $(66 ; 78 \%)$ were reported from the USA or Canada (10; $12 \%)$. A wide range of disciplines were represented with the most common being general surgery, internal medicine, orthopedic surgery, and pediatrics. Themes (number of reports) included trainee characteristics $(n=24)$, project characteristics $(n=8)$, mentoring/supervision $(n=11)$, and programmatic aspects $(n=57)$. Although variable results were observed, research productivity tended to be higher with prior research experience, later years of training, male gender, and pursuit of a postgraduate degree. Few project related aspects of success were identified. Trainee publication was associated with mentors with higher rank, publication productivity, and supportive academic environments. Training programs with organised programs/curricula including protection of time for research were associated with increased productivity as were provision of incentives or rewards but not mandatory requirements.
\end{abstract}

Conclusion: This review identifies several trainee characteristics, project and mentor aspects, and programmatic aspects associated with increased productivity that may serve as a useful resource for trainees and graduate medical education training programs.

Keywords: Medical training, Research productivity, Postgraduate, Trainees

\section{Introduction}

Research is recognized as an important component of graduate medical education training, and active participation is mandatory in many programs globally $[1,2]$. Trainees may benefit by participation in research through

\footnotetext{
*Correspondence: Kevin.laupland@qut.edu.au

1 Department of Intensive Care Services, Royal Brisbane and Women's

Hospital, Level 3 Ned Hanlon Building, Butterfield Street, Brisbane,

Queensland 4029, Australia

Full list of author information is available at the end of the article
}

an improved undertanding of and ability to apply studies reported in the literature, which may in turn translate to better performance on clinical examinations and patient outcomes [3]. In addition, research productivity during graduate medical education has been shown in many disciplines to increase the likelihood of acceptance into advanced training positions and predicts success in subsequent academic careers $[4,5]$. Although research is a common requirement, a minority of graduate medical trainees publish their work in peer-reviewed journals,

(c) The Author(s) 2021. Open Access This article is licensed under a Creative Commons Attribution 4.0 International License, which permits use, sharing, adaptation, distribution and reproduction in any medium or format, as long as you give appropriate credit to the original author(s) and the source, provide a link to the Creative Commons licence, and indicate if changes were made. The images or other third party material in this article are included in the article's Creative Commons licence, unless indicated otherwise in a credit line to the material. If material is not included in the article's Creative Commons licence and your intended use is not permitted by statutory regulation or exceeds the permitted use, you will need to obtain permission directly from the copyright holder. To view a copy of this licence, visit http://creativecommons.org/licenses/by/4.0/. The Creative Commons Public Domain Dedication waiver (http://creativeco mmons.org/publicdomain/zero/1.0/) applies to the data made available in this article, unless otherwise stated in a credit line to the data. 
and this outcome is highly variable among individuals, disciplines, and institutions [6].

Knowledge of the determinants of successful research performance during graduate medical education is important for both individuals and for training programs. Although systematic reviews summarizing factors associated with successful performance of graduate medical education research have been reported, they have either been limited to interventions at the programmatic level, highly selected jurisdictions or interventions, or have included non-research related scholarly activities [7-10]. The objective of this study was to conduct a structured review of the literature to broadly identify factors associated with research productivity during graduate medical education to serve as a resource for both clinical trainees and program directors.

\section{Methods}

The study protocol was established a priori and was developed as outlined by the members of the Joanna Briggs Institute and members of the Joanna Briggs Collaborating Centres [11].

The specific research questions were "what evidence is there to guide successful completion and publication of a graduate medical education trainee research project with respect to":

1) Trainee background and characteristics;

2) Project characteristics;

3) Mentoring/supervision; and

4) Programmatic aspects.

\section{Eligibility criteria}

Studies of any methodology that addressed one or more of the research questions were considered. Clinical studies were selected for inclusion if the primary focus was on physician graduate clinical trainees and the topic was conduct of novel research projects. Our focus was on clinical trainees who were enrolled in core training programs (i.e. internship, residency, registrar) following medical school with primary goal of granting of initial speciality designation and/or licensure. Research conducted by fellows of a (sub)specialty college post-certification were excluded in order to reduce the confounding effects of trainees who were licensed physicians/consultants who were pursuing advanced level research experiences. Program descriptions, quality improvement initiatives, or opinion surveys that did not include a comparative evaluation component were excluded as were case reports, reviews, editorials, or reports published only as abstracts. Our primary outcome was publication in a peer-reviewed journal.

\section{Search methodology}

An initial electronic search of titles and abstracts was conducted using the Pubmed, EMBASE, and CINAHL databases from inception through to 7 April, 2021. The search used the terms "resident"[Title/Abstract] OR "registrar"[Title/Abstract] OR "trainees"[Title/Abstract]) AND "research"[Title]. The search was not limited by design, language, or year. The titles and abstracts were independently screened for potential inclusion by two reviewers (KBL, JD) with consensus review of discrepant results. Full length articles were then retrieved and reviewed by one author (KBL) with application of eligibility criteria. Additional relevant publications were identified by scanning of bibliographies of included articles and review articles [7-10].

Following the compilation of a list of articles for inclusion, data was extracted with results mapped according to the pre-specified themes. Studies were classified as prepost intervention (i.e. historical control cohort), cohort (observational group or series with subsequent outcome over a time period), survey/cross sectional (performed at a defined time point), and other. Where other outcome measures were bundled with publications we limited data inclusion to publications only where data were available. Where there was inadequate data to analyse publications separately we only included studies reporting a composite outcome measure where publication was a major component.

Analysis was descriptive. Study results were grouped into themes according to the research questions. We accepted and reported statistical significance of individual comparisons from the original studies without secondary or confirmatory analysis and did not calculate summary statistics or perform meta-analysis. Statistical significance was defined by a $p$-value of $\leq 0.05$.

\section{Results}

Electronic searches conducted using Pubmed $(n=1522)$, EMBASE $(n=2017)$, and CINAHL $(n=1095)$ databases retrieved a total of 4634 citations of which 2703 remained following duplicate removal. An additional 37 citations were identified from bibliographic review of references of included articles and 129 full text articles were retrieved for full text review. After application of study inclusion and exclusion criteria, 85 articles were included in the final review as detailed in Fig. 1. The details of each of the studies are included in supplementary Table 1.

Of the 85 included studies, 66 (78\%) were reported from the USA, with ten (12\%) from Canada, two (2\%) from Thailand, and one (1\%) each from Australia/New Zealand, USA/Canada, Europe, Germany, India, Japan, and Lebanon. Study designs were pre-post (40; 47\%), 


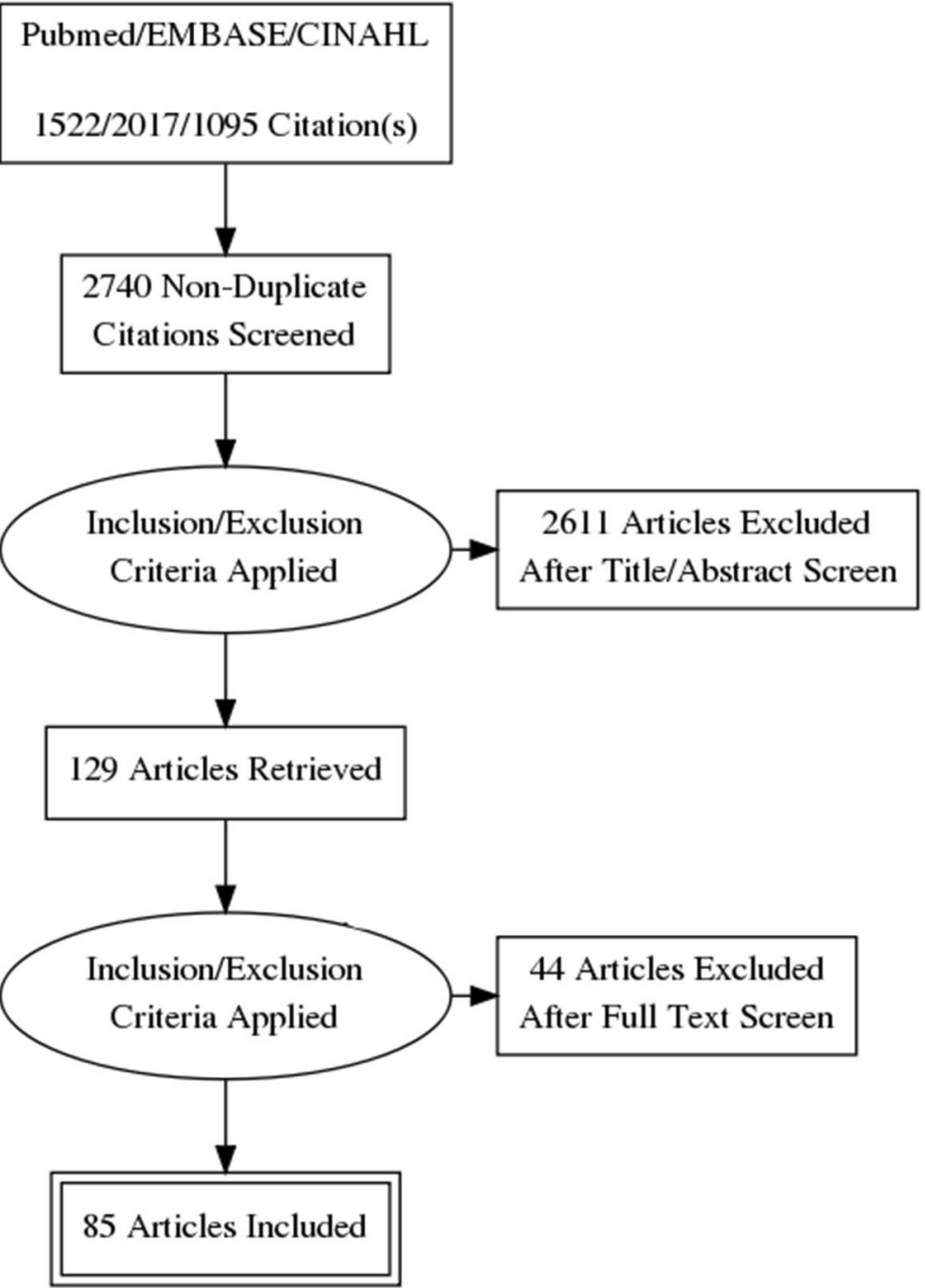

Fig. 1 PRISMA diagram of study selection

cohort (23; 27\%), survey/cross sectional (21; 25\%), and one study was a mixed methods (pre-post with cohort). Among the 77 studies where the number of subjects were reported or could be estimated from the manuscript, the median number was 115 with a range from 14 to 1690 . A wide range of disciplines were represented with the most common being general surgery, internal medicine, orthopedic surgery, and pediatrics as shown in Table 1. Studies overall included subjects from as early as 1965 to as late as 2019 , and the median start and end dates were 2004 and 2012, respectively.

\section{Trainee background and characteristics}

Twenty-four studies included examination of aspects related to trainee attributes or characteristics that were associated with research productivity [12-35], and these were largely related to past research performance, clinical training experience, and gender.

Six studies examined prior publication record related to past research experience [12, 13, 22, 31, 34, 35], of which three found this to be associated with increased productivity [12, 34, 35]. One study also observed that domestic medical graduates were more likely to publish than those who attended foreign medical schools [12]. There were mixed effects associated with trainees who had prior or concomitant pursuit of a higher postgraduate degree (i.e. MSc, MPH, PhD). Among a total of 13 studies, this was associated with higher productivity in six $[15,23-26,34]$, no difference in five [13,21,28,31,33], and in two studies this was associated with lower productivity $[18,19]$. Of four studies that looked at past research experience that was not specifically related to higher degree $[12,26,29$, 
Table 1 Distribution of training disciplines of included studies

\begin{tabular}{ll}
\hline Discipline & Number (\%) \\
\hline Internal Medicine & $11(13 \%)$ \\
Surgery & \\
$\quad$ General & $11(13 \%)$ \\
Orthopedic & $8(9 \%)$ \\
Urology & $6(7 \%)$ \\
Otolaryngology & $4(5 \%)$ \\
Plastic & $3(4 \%)$ \\
Neurosurgery & $1(1 \%)$ \\
Obstetrics and Gynecology & $1(1 \%)$ \\
Other & $2(2 \%)$ \\
Pediatrics & $8(9 \%)$ \\
Radiation Oncology & $6(7 \%)$ \\
Family Medicine & $5(6 \%)$ \\
Psychiatry & $5(6 \%)$ \\
Anesthesia & $3(4 \%)$ \\
Emergency Medicine & $3(4 \%)$ \\
Physical Medicine and Rehabilitation & $3(4 \%)$ \\
Neurology & $2(2 \%)$ \\
Psychosomatic and General Internal Medicine & $1(1 \%)$ \\
Radiology & $1(1 \%)$ \\
Other & $1(1 \%)$ \\
\hline
\end{tabular}

32], three found this to be a significant factor associated with graduate medical training research productivity $[12$, $26,32]$.

Clinical training experiences were associated with productivity. Most studies found that later years of training $[14,17,23,29,31,32]$ were associated with higher publication rates with no difference observed in three studies [12, 21, 27], and an inverse effect in one [22]. Notably, one study found that residents who reported doing a higher number of histories and physicals per week had higher research productivity [26]. Trainees who reported an expressed interest in doing research were more productive in three $[16,23,29]$ studies with only one showing no difference with this variable [33].

Eleven studies examined the gender of trainees as a determinant of publication success and found that males had higher productivity in five studies [18-20, 29, 32], females in one study [26], and no difference was observed in five studies [12, 13, 17, 21, 30].

\section{Project characteristics}

Eight studies examined aspects of specific projects in relation to success with subsequent publication $[12,16$, 21, 36-40]. Although specific project supports played a role, the main findings were related to the choice of study designs and subsequent publication success.
Vinci et al examined factors associated with a successful research productivity (publication or presentation) among pediatric trainees and found that this was significantly related to the project type [21]. While success occurred with $38 \%$ of educational/curriculum, $54 \%$ of clinical, and $57 \%$ of basic science projects, only $6 \%$ of "enhanced clinical experience" projects, and no career planning projects were successfully published. On the other hand, Atreya and colleagues examined 94 studies conducted by American Internal Medicine trainees of which $32 \%$ were retrospective cohorts, $44 \%$ were cross sectional, $4 \%$ were prospective cohorts, and $20 \%$ were other designs [12]. However, there was no significant association of research productivity with study design [12]. Yumeen and colleagues reported that among projects presented at a Plastic Surgery research day, subsequent publications rates were higher for basic science $(9 / 14 ; 64 \%)$ as compared to clinical $(42 / 113 ; 37 \%)$ topics [40].

Taschanchai and Mahachoklertwattana found that availability of funding influenced the types of successful studies published during Pediatrics residency in Thailand, with increasing funds associated with fewer retrospective studies and increasing cross sectional and prospective studies [38]. Winn et al. found no difference in publication rates among residents who received project funding grants or not in an American Pediatrics program [39]. Among three studies that looked at the availability of a research assistant, two showed a positive effect [16, 36] with no effect in one [12]. The latter study also found that biostatistical support was associated with publication [12] but this was not deemed to be of benefit in another study [37].

\section{Mentoring/supervision}

Eleven studies examined mentor and/or supervisory characteristics in relation to subsequent success in publication of resident projects [6, 12, 21, 22, 41-47]. These mentoring aspects were specifically related to direct project supervision in some cases [12, 21, 22, 41, 42], whereas the mentoring environment was a consideration in others $[6,41,43-48]$.

Atreya et al found that among Internal Medicine trainees, successful publication was significantly higher with a mentor who had an advanced degree ( $75 \%$ vs $50 \%$ ), intramural funding ( $73 \%$ vs $52 \%$ ), and five or more publications at study conception (96\% vs 71\%) [12]. However, external funding and protected time for the mentor were not associated with publications [12]. In a survey of Physical Medicine and Rehabilitation program directors in the USA, having a mentor external to the department was associated with a lower rate of publication [41]. Susarla et al found that Plastic Surgery mentor rank of associate/ 
full professor versus lower ranks were associated with higher publication success [22]. Levitt et al found no significant effect of mentor financial support, research award, or protected time on publications productivity in Emergency Medicine training programs [42]. Vinci and colleagues reported that mentor ratings were associated with research productivity [21].

Aspects of the mentoring environment included availability of a mentor [43, 46], guidelines about mentor choice [41], and having a residency director with increased activity of publishing $[44,45]$ which were associated with increased publication output. Lepard et al surveyed neurosurgical programs in the USA and found that programs reporting journal clubs with mentors with epidemiology and biostatistics expertise, but not regular mentor meetings associated with increased resident publications [27]. Older, more established residency programs have been associated with improved publication outcomes among trainees [44]. Similarly, trainees in larger and/or tertiary care/university hospitals have demonstrated higher publication rates than those in smaller community-based hospitals $[6,46,48]$. One study of Family Medicine residents from Canada found that encouragement and support to publish finished projects resulted in increased publications [47].

\section{Programmatic aspects}

These included programmatic/curricular aspects $[23,27$, $36,41,46,49-81]$, management of trainee time [13, 23, $26,27,41,42,46,65,74,78,82-92]$, mandatory requirements [16, 27, 41, 72, 86, 91-94] and rewards [42, 95, 96].

Most of the included literature surrounding aspects related to trainee publications were related to programmatic aspects, most commonly by implementation of a research program and/or curriculum with measure of publication output changes using pre-post designs. Among the 38 studies that evaluated multifaceted programs/curricula of varying types, most were associated with increased output [36, 46, 49-70, 80, 81], whereas 11 showed no significant effect [27, 41, 71-79], and one was associated with lower publication output [23].

Protection of trainee time for research found this to be a significant productivity factor in 12 studies [13, 23, $26,27,74,82-88]$, whereas this was not significant in five [41, 42, 89-91]. Similarly, a specified/scheduled research block of research time or formalized research rotation increased productivity $[46,65,78,88,92]$ in five studies whereas it was of no effect in two [36,91]. Williams et al found that provision of research time in a longitudinal as compared to block or no time schedule was associated with a significant greater output of $1.9 \pm 1.8$ versus $1.0 \pm 1.0$ publication [85]. A dose response was found by Lee et al [82] with increasing residency research time from $0,3-4,6$, and 12 months correlated with increased median residency publications of $1,2,3$, and 5 , respectively.

Institution of a mandatory research requirement had limited effect with only two $[92,93]$ of six papers finding a positive effect [16, 41, 72, 91-93]. Similarly, a mandatory manuscript/publication requirement increased publication in only one [93] of three studies [27, 93, 94]. Notably, in one study the requirement was associated with an adverse shift away from first author position [94]. Fisher found that an intervention whereby regular notification of research requirements and tracking of progress was associated with an increase in publications in an American surgical training program [86].

Rewards for productivity demonstrated significant benefit in two studies [95, 96]. Chang and colleages reported a pre-post study where a points based monetary reward system was implemented for academic productivity which led to a tripling of the average annual resident publication output [95]. Larsen examined the effect of a monetary incentive which although increased publications it was associated with a shift away from basic science projects and toward systematic reviews [96]. Research awards were not associated with increased publications in one survey of Emergency Medicine programs [42].

\section{Discussion}

This report reviews graduate medical education trainee research productivity and identifies several determinants of outcome related to trainees, mentors, and programs. We identified a moderate sized body of literature of which most was related to programmatic aspects and very little specifically related to individual project characteristics. Individual and mentor factors are generally associated with experience, dedicated research time, and specific training. Implementation of research programs and/or curricula are broadly associated with improved publication outcomes and monetary incentives rather than mandatory requirements improves research productivity. These findings should be of value as a resource for individual trainees and to inform training programs in devising means to improve research productivity associated with graduate medical education.

Although there were mixed findings, generally speaking the literature indicates that trainees with prior research experience, previous or concomitant higher research degrees, and those at later years of training have increased research productivity. While the latter aspect may simply be a measure for increasing time of opportunity, greater prior experience(s) and past or concurrent pursuit of postgraduate degrees likely reflects increases in research related knowledge and aptitude. It 
is not surprising that trainee attitude towards research is associated with productivity $[16,23,29]$. It is a somewhat surprising finding that one study found that trainees on "busier" clinical services had higher research productivity despite presumably having less available time for activities not directly related to patient care [26]. The observation among included studies that males tend to have higher research productivity during graduate medical education is important. Further studies are needed in order to define whether this observation may be related to confounding factors (i.e. past experience, interest in research), systemic gender bias, and/or differential opportunity [97].

A limited body of literature evaluated project-specific and mentoring related aspects and research productivity. The small number of studies related to specific project types and aspects precludes general summary comments and identifies this as a priority for further investigation. With regards to mentorship, more experienced mentors with prior track record of productivity who are working within a research intensive department/environment are associated with supervision of trainee research publication. In recent decades many jurisdictions have re-distributed provision of medical education with less emphasis on large tertiary care urban settings with a shift to smaller communities. However, failure to concomitantly increase research mentors in these distributed centres presents a significant risk to trainee research productivity and merits further attention [98].

Most of the literature surrounding research productivity during graduate medical education has related to programmatic interventions and has been the focus of four previous systematic reviews [7-10]. It is important to note that while we identified more than 50 publications investigating this topic, most of the included studies relate to implementation of multi-faceted programs or bundled interventions such that individual variables related to outcomes are difficult to assess. In addition, this body of literature largely consists of studies employing pre-post historical cohort designs that have major inherent limitations. Prospective interventional studies are needed to best define ways to improve graduate medical education research productivity.

Although this review benefits from a structured approach, there are some limitations that merit discussion. We excluded conference proceedings and abstracts and as a result there may be additional relevant information that was not included. Additionally, our search strategy was simplistic. While we are confident that we identified relevant articles through our protocol including bibliographic review of included papers, it remains a possibility that we may have missed inclusion of some relevant articles. Another consideration is that abstraction of the results from the full text articles was conducted by one author raising the possibililty of error and/or bias in that regard. Ideally this would have been performed independently by more than one author and is a limitation of this report. It is notable that we did not formally evaluate statistical significance of individual studies nor try to calculate summary statistics [11]. Furthermore, we focussed on indexed publications as our primary outcome. While other scholarly activities have merit, publications in indexed journals represent the most widely accepted objective outcome of research productivity. Finally, while we included an assessment of gender, we did not specifically examine other aspects of potential discrimination (e.g. race) that could influence research productivity during training.

To conclude, this review details several trainee characteristics, mentor attributes, and programmatic aspects that are associated with increased graduate medical trainee research productivity. This information should be of value to both trainees and programs with their goals of improving research publication productivity during graduate medical education.

\section{Supplementary Information}

The online version contains supplementary material available at https://doi. org/10.1186/s12909-021-03010-1.

\section{Additional file 1.}

\section{Authors' contributions}

$\mathrm{KBL}$ takes responsibility for the content of the manuscript including data and analysis, as the guarantor. KBL and JD made substantial contribution to the conception and design of the work. All authors were involved in the acquisition of data. KBL and JD were involved in the analysis and interpretation of data. All authors were involved in drafting and revising the manuscript and approved the version to be published.

Funding

Nil sources of funding.

Availability of data and materials

Not applicable.

\section{Declarations}

Ethics approval and consent to participate Not applicable.

Consent for publication

Not applicable.

Competing interests

The authors declare that they have no competing interests.

\section{Author details}

${ }^{1}$ Department of Intensive Care Services, Royal Brisbane and Women's Hospital, Level 3 Ned Hanlon Building, Butterfield Street, Brisbane, Queensland 4029, Australia. ${ }^{2}$ Queensland University of Technology (QUT), Brisbane, Queensland, Australia. ${ }^{3}$ Faculty of Medicine, University of Queensland, Brisbane, Queensland, Australia. 
Received: 1 July 2021 Accepted: 29 October 2021

Published online: 09 November 2021

\section{References}

1. Stehlik P, Noble C, Brandenburg C, Fawzy P, Narouz I, Henry D, et al. How do trainee doctors learn about research? Content analysis of Australian specialist colleges' intended research curricula. BMJ Open. 2020;10(3):e034962.

2. ACGME Common Program Requirements (Residency), Accreditation Council for Graduate Medical Education. Available at: https://www. acgme.org/Portals/0/PFAssets/ProgramRequirements/CPRResiden cy2020.pdf Accessed 16 April 2021.

3. Jones A, Smiley W, Biester TW, Malangoni MA. Completion of research training during residency is associated with American Board of Surgery examination performance. J Am Coll Surg. 2014;219(4):e96.

4. Ahmad HF, Jarman BT, Kallies KJ, Shapiro SB. An analysis of future publications, career choices, and practice characteristics of research presenters at an American College of Surgeons state conference: a 15-year review. J Surg Educ. 2017;74(5):857-61.

5. Andriole DA, Klingensmith ME, Fields RC, Jeffe DB. Is dedicated research time during surgery residency associated with Surgeons' future career paths?: a National Study. Ann Surg. 2020;271(3):590-7.

6. Ishiguro A, Nomura O, Michihata N, Kobayashi T, Mori R, Nishiya K, et al. Research during pediatric residency training: a Nationwide study in Japan. JMA J. 2019;2(1):28-34

7. Hebert RS, Levine RB, Smith CG, Wright SM. A systematic review of resident research curricula. Acad Med. 2003;78(1):61-8.

8. Stevenson MD, Smigielski EM, Naifeh MM, Abramson EL, Todd C, Li ST. Increasing scholarly activity productivity during residency: a systematic review. Acad Med. 2017;92(2):250-66.

9. Wood W, McCollum J, Kukreja P, Vetter IL, Morgan CJ, Hossein Zadeh Maleki A, et al. Graduate medical education scholarly activities initiatives: a systematic review and meta-analysis. BMC Med Educ. 2018;18(1):318.

10. Zimmerman R, Alweis R, Short A, Wasser T, Donato A. Interventions to increase research publications in graduate medical education trainees: a systematic review. Arch Med Sci. 2019;15(1):1-11.

11. Peters MD, Godfrey CM, Khalil H, McInerney P, Parker D, Soares CB. Guidance for conducting systematic scoping reviews. Int J Evid Based Healthcare. 2015;13(3):141-6.

12. Atreya AR, Stefan M, Friderici JL, Kleppel R, Fitzgerald J, Rothberg MB. Characteristics of successful internal medicine resident research projects: predictors of journal publication versus abstract presentation. Acad Med. 2018;93(8):1182-8.

13. Chen JX, Kozin ED, Sethi RK, Remenschneider AK, Emerick KS, Gray ST. Increased resident research over an 18-year period: a single Institution's experience. Otolaryngol Head Neck Surg. 2015;153(3):350-6.

14. Fayad F, Aitisha Tabesh O, Lotfi T, Haddad F, Nemr E. Engagement of medical specialty trainees in research: experience at a Lebanese medical school. East Mediterr Health J. 2020;26(9):1018-24.

15. Isom CA, Bisgaard EK, Campbell KM, Courtney C, Erickson C, Faber DA et al. Does intentional support of degree programs in general surgery residency affect research productivity or pursuit of academic surgery? A Multi-Institutional Study. J Surg Educ. 2020;77(6):e34-8.

16. McHenry MS, Abramson EL, MCKenna MP, Li ST. Research in pediatric residency: National Experience of pediatric chief residents. Acad Pediatr 2017;17(2):144-8

17. Mutsaers A, Jia S, Warner A, Nguyen TK, Laba JM, Palma DA. Research Productivity of Canadian Radiation Oncology Residents: A Time-Trend Analysis. Curr Oncol. 2020;28(1):4-12.

18. Rowley JP, Sindhu KK, Smith WH, Nehlsen AD, Smith AW, Lehrer EJ, et al. Radiation oncology resident research productivity in the United States: 2015 to 2019. Int J Radiat Oncol Biol Phys. 2021:109(4):1111-8.

19. Verma V, Burt L, Gimotty PA, Ojerholm E. Contemporary trends in radiation oncology resident research. Int J Radiat Oncol Biol Phys. 2016;96(4):915-8.

20. Vernuccio F, Arzanauskaite M, Turk S, Torres ET, Choa JMD, Udare AS, et al. Gender discrepancy in research activities during radiology residency. Insights Imaging. 2019;10(1):125.
21. Vinci RJ, Bauchner H, Finkelstein J, Newby PK, Muret-Wagstaff S, Lovejoy FH Jr. Research during pediatric residency training: outcome of a senior resident block rotation. Pediatrics. 2009:124(4):1126-34.

22. Susarla SM, Lopez J, Mundinger GS, Lifchez SD, Redett RJ. Abstract presentations by residents at an intramural research day: what factors affect publication? J Surg Educ. 2015;72(4):566-71.

23. Chan RK, Lockyer J, Hutchison C. Block to succeed: the Canadian orthopedic resident research experience. Can J Surg. 2009;52(3):187-95.

24. Joshua Smith J, Patel RK, Chen X, Tarpley MJ, Terhune KP. Does intentional support of degree programs in general surgery residency affect research productivity or pursuit of academic surgery? J Surg Educ. 2014;71(4):486-91.

25. Shah PM, Edwards BL, Dietch ZC, Sawyer RG, Schroen AT. Relationship of a second professional degree to research productivity of general surgery residents. J Surg Educ. 2017;74(1):124-30.

26. Gutovich JM, Den RB, Werner-Wasik M, Dicker AP, Lawrence YR. Predictors of radiation oncology resident research productivity. J Am Coll Radiol. 2013:10(3):185-9.

27. Lepard J, Shank C, Agee B, Hadley M, Walters B. Neurosurgical resident research education: a survey of United States residency program directors. J Neurosurg. 2019:1-10.

28. Tsai AC, Ordóñez AE, Reus VI, Mathews CA. Eleven-year outcomes from an integrated residency program to train research psychiatrists. Acad Med. 2013;88(7):983-8.

29. Abramson EL, Naifeh MM, Stevenson MD, Mauer E, Hammad HT, Gerber LM, et al. Scholarly activity training during residency: are we hitting the mark? A National Assessment of pediatric residents. Acad Pediatr. 2018;18(5):542-9.

30. West CP, Halvorsen AJ, McDonald FS. Scholarship during residency training: a controlled comparison study. Am J Med. 2011;124(10):983-7 e981.

31. Andrews JM, Abdolell M, Norman RW. Canadian urology resident scholarly performance. Can Urol Assoc J. 2013;7(5-6):E402-6.

32. Gill S, Levin A, Djurdjev O, Yoshida EM. Obstacles to residents' conducting research and predictors of publication. Acad Med. 2001;76(5):477

33. Carter S, Liew S, Brown G, Moaveni AK. Barriers to completion of research projects among Orthopaedic trainees. J Surg Educ. 2018;75(6):1630-4

34. Hellenthal NJ, Ramírez ML, Yap SA, Kurzrock EA. Manuscript publication by urology residents and predictive factors. J Urol. 2009;181(1):281-6 discussion 286-287

35. Kohlert S, Zuccaro L, McLean L, Macdonald K. Does medical school research productivity predict a resident's research productivity during residency? J Otolaryngol Head Neck Surg. 2017;46(1):34.

36. Ahmad S, De Oliveira GS Jr, McCarthy RJ. Status of anesthesiology resident research education in the United States: structured education programs increase resident research productivity. Anesth Analg. 2013;116(1):205-10.

37. Thiruthaneeswaran N, Turner S, Milross C, Gogna K. Promoting a research culture among junior radiation oncologists: outcomes from the introduction of the Australian and New Zealand research requirement in training. Clin Oncol (R Coll Radiol). 2014;26(3):162-73

38. Taschanchai N, Mahachoklertwattana P. Thirty-year pediatric residency research and publication productivity: association with research funding. J Med Assoc Thail. 2021;104(3):337-43.

39. Winn AS, Nigrovic LE, Lovejoy FH, Sandora TJ. Impact of a resident research Grant on scholarly output during pediatric residency. Acad Pediatr. 2019;19(4):477-9.

40. Yumeen S, Ho ES, Wong K, Borschel GH. What factors influence resident research publication in the division of plastic surgery? J Surg Educ. 2018;75(2):409-16.

41. Blake DJ, Lezotte DC, Yablon S, Rondinelli RD. Structured research training in residency training programs. The impact on the level of resident research activity. Am J Phys Med Rehabil. 1994;73(4):245-50.

42. Levitt MA, Terregino CA, Lopez BL, Celi C. Factors affecting research directors' and residents' research experience and productivity in emergency medicine training programs. Acad Emerg Med. 1999;6(4):356-9.

43. Mills OF, Zyzanski SJ, Flocke S. Factors associated with research productivity in family practice residencies. Fam Med. 1995;27(3):188-93.

44. Crawford P, Seehusen D. Scholarly activity in family medicine residency programs: a national survey. Fam Med. 2011:43(5):311-7. 
45. Durning SJ, Cation LJ, Ender PT, Gutierrez-Nunez JJ. A resident research director can improve internal medicine resident research productivity. Teach Learn Med. 2004;16(3):279-83.

46. Strauss GD, Yager J, Offer D. Research training in psychiatry: a survey of current practices. Am J Psychiatry. 1980;137(6):727-9.

47. Grzybowski S, Thommasen HV, Mills J, Herbert CP. Review of University of British Columbia Family Practice Resident Research projects 19901997. Fam Med. 1999;31(5):353-7.

48. Morgan PB, Sopka DM, Kathpal M, Haynes JC, Lally BE, Li L. First author research productivity of United States radiation oncology residents: 2002-2007. Int J Radiat Oncol Biol Phys. 2009;74(5):1567-72.

49. Lohr J, Smith JM, Welling R, Engel A, Hasselfeld K, Rusche J. Stimulating resident research in a general surgery residency community program. Curr Surg. 2006;63(6):426-34.

50. Arora V, Bell PF, Hagberg S. Cultivating change: engaging residents in research. Int J Psychiatry Med. 2020;55(5):376-83.

51. Frankel WC, Scott BG, Massarweh NN, Silberfein EJ, Zhang Q, Rosengart TK, et al. A multifaceted research engagement program improved the academic productivity of general surgery residents. J Surg Educ. 2020;77(5):1082-7.

52. Manring MM, Panzo JA, Mayerson JL. A framework for improving resident research participation and scholarly output. J Surg Educ. 2014;71(1):8-13.

53. Millis SR, Campagnolo DI, Kirshblum S, Elovic E, Jain SS, DeLisa JA. Improving resident research in physical medicine and rehabilitation: impact of a structured training program. J Spinal Cord Med. 2004;27(5):428-33.

54. Oliver JJ, Ross JM, Davis WT, Ng PC, Long B, Weymouth WL, et al. The development of an emergency medicine resident research program in the United States military. Mil Med. 2019;184(11-12):e622-5.

55. Panchal AR, Denninghoff KR, Munger B, Keim SM. Scholar quest: a residency research program aligned with faculty goals. West J Emerg Med. 2014;15(3):299-305.

56. Robbins L, Bostrom M, Marx R, Roberts T, Sculco TP. Restructuring the orthopedic resident research curriculum to increase scholarly activity. J Grad Med Educ. 2013;5(4):646-51.

57. Torres D, Gugala Z, Lindsey RW. A dedicated research program increases the quantity and quality of orthopaedic resident publications. Clin Orthop Relat Res. 2015;473(4):1515-21.

58. Lennon RP, Oberhofer AL, McNair V, Keck JW. Curriculum changes to increase research in a family medicine residency program. Fam Med. 2014;46(4):294-8.

59. Rothberg MB, Kleppel R, Friderici JL, Hinchey K. Implementing a resident research program to overcome barriers to resident research. Acad Med. 2014;89(8):1133-9.

60. Konstantakos EK, Laughlin RT, Markert RJ, Crosby LA. Assuring the research competence of orthopedic graduates. J Surg Educ. 2010;67(3):129-34.

61. Roane DM, Inan E, Haeri S, Galynker II. Ensuring research competency in psychiatric residency training. Acad Psychiatry. 2009;33(3):215-20.

62. Ruiz J, Wallace EL, Miller DP, Loeser RF, Miles M, Dubose TD, et al. A comprehensive 3-year internal medicine residency research curriculum. Am J Med. 2011;124(5):469-73.

63. Farrokhyar F, Amin N, Dath D, Bhandari M, Kelly S, Kolkin AM, et al. Impact of the surgical research methodology program on surgical residents' research profiles. J Surg Educ. 2014;71(4):513-20.

64. Hoedebecke K, Rerucha C, Runser L. Increase in residency scholarly activity as a result of resident-led initiative. Fam Med. 2014;46(4):288-90.

65. Sakai T, Emerick TD, Metro DG, Patel RM, Hirsch SC, Winger DG, et al. Facilitation of resident scholarly activity: strategy and outcome analyses using historical resident cohorts and a rank-to-match population. Anesthesiology. 2014;120(1):111-9.

66. Mezzacappa E, Hamoda HM, DeMaso DR. Promoting scholarship during child and adolescent psychiatry residency. Acad Psychiatry. 2012;36(6):443-7.

67. Kichler K, Kozol R, Buicko J, Lesnikoski B, Tamariz L, Palacio A. A structured step-by-step program to increase scholarly activity. J Surg Educ. 2014;71(6):e19-21.

68. Hepburn MJ, Battafarano DF, Enzenauer RJ, Salzberg DJ, Murphy FT, Parisek RA, et al. Increasing resident research in a military internal medicine program. Mil Med. 2003;168(4):341-5.
69. Eckert J, Vaida SJ, Bezinover D, McCloskey DE, Mets B. The resident academic project program: a structured approach to inspiring academic development during residency training. A A Case Rep. 2016;6(4):95-9.

70. Kurahara DK, Kogachi K, Yamane M, Ly CL, Foster JH, Masaki-Tesoro T, et al. A pediatric residency research requirement to improve collaborative resident and faculty publication productivity. Hawaii J Med Public Health. 2012;71(8):224-8.

71. Allen L, Vogt K, Mele T, Ott M, Leslie K, Colquhoun P. Evaluating the impact of a resident research program in general surgery. Can Med Educ J. 2017;8(3):e13-20.

72. Harrison LM, Woods RJ, McCarthy MC, Parikh PP. Development and implementation of a sustainable research curriculum for general surgery residents: A foundation for developing a research culture. Am J Surg. 2020;220(1):105-8.

73. Robbins MS, Haut SR, Lipton RB, Milstein MJ, Ocava LC, Ballaban-Gil K, et al. A dedicated scholarly research program in an adult and pediatric neurology residency program. Neurology. 2017;88(14):1366-70.

74. Papasavas P, Filippa D, Reilly P, Chandawarkar R, Kirton O. Effect of a mandatory research requirement on categorical resident academic productivity in a university-based general surgery residency. J Surg Educ. 2013;70(6):715-9.

75. Carter AE, Anderson TS, Rodriguez KL, Hruska KL, Zimmer SM, Spagnoletti $\mathrm{CL}$, et al. A program to support scholarship during internal medicine residency training: impact on academic productivity and resident experiences. Teach Learn Med. 2019;31(5):552-65.

76. Löwe B, Hartmann M, Wild B, Nikendei C, Kroenke K, Niehoff D, et al. Effectiveness of a 1-year resident training program in clinical research: a controlled before-and-after study. J Gen Intern Med. 2008;23(2):122-8.

77. Desbiens NA. A departmental experience in promoting oral and poster presentations. Teach Learn Med. 2008;20(3):254-60.

78. Kanna B, Deng C, Erickson SN, Valerio JA, Dimitrov V, Soni A. The research rotation: competency-based structured and novel approach to research training of internal medicine residents. BMC Med Educ. 2006;6:52.

79. Roth DE, Chan MK, Vohra S. Initial successes and challenges in the development of a pediatric resident research curriculum. J Pediatr. 2006;149(2):149-50.

80. Holoyda K, Donato D, Veith J, Simpson A, Moores N, Agarwal J. A dedicated quarterly research meeting increases resident research productivity. J Surg Res. 2019;241:103-6.

81. Alweis $R$, Wenderoth $S$, Donato A. Effectiveness of iterative interventions to increase research productivity in one residency program. J Commun Hosp Intern Med Perspect. 2015;5(6):29203.

82. Lee A, Namiri N, Rios N, Enriquez A, Hampson LA, Pruthi RS, et al. Dedicated residency research time and its relationship to urologic career academic success. Urology. 2021;148:64-9.

83. Levy DM, Luchetti TJ, Levine BR. Have residents produced more research since the inception of the 80-hour workweek? lowa. Orthop J. 2017;37:205-9.

84. Mlynarczyk CM, Finkelstein JB, Onyeji IC, Van Batavia JP, Rosoff JS, Badalato GM. What's in a number? Examining the effect of a dedicated research year on $\mathrm{H}$-index and fellowship decision-making. Urology. 2016;98(1):27-31.

85. Williams BR, Agel JA, Van Heest AE. Protected time for research during Orthopaedic residency correlates with an increased number of resident publications. J Bone Joint Surg Am. 2017;99(13):e73.

86. Fisher C, Baker MK. Improving participation and quality of clinical research in a university-based general surgery residency program. Am Surg. 2010;76(7):741-2.

87. Finkelstein JB, Van Batavia JP, Rosoff JS. The difference a year can make: academic productivity of residents in 5 vs 6 -year urology programs. Urology. 2015;86(2):220-2.

88. Khurana D, Vishnu VY, Vinny PW, Rishi V. Influence of a publication rotation in a neurology residency program in a developing country. Neurology. 2015;84(2):197-9.

89. Krueger CA, Hoffman JD, Balazs GC, Johnson AE, Potter BK, Belmont PJ Jr. Protected resident research time does not increase the quantity or quality of residency program research publications: a comparison of 3 orthopedic residencies. J Surg Educ. 2017;74(2):264-70.

90. Villwock JA, Hamill CS, Nicholas BD, Ryan JT. Otolaryngology residency program research resources and scholarly productivity. Otolaryngol Head Neck Surg. 2017;156(6):1119-23. 
91. Taniguchi MH, Johnson PD. Rehabilitation resident academic productivity. Report on 1993 graduates. Am J Phys Med Rehabil. 1994;73(4):240-4.

92. Thomas JB, Cofer JB, Lewis PL, Burns RP. Clinical research during surgery residency: the Chattanooga approach. Curr Surg. 2000;57(2):135-9.

93. Sabir M, Penney DG, ReMine SG, Mittal VK. Scholarly activities--essential to surgical education. Curr Surg. 2003;60(4):459-62.

94. Tintara H, Lumbiganon P, Preutthipan S, Tannirandorn Y. Research publication by the Royal Thai College of obstetricians and gynecologists residency training program, 1994-2003. J Med Assoc Thail. 2007;90(5):870-5.

95. Chang CW, Mills JC. Effects of a reward system on resident research productivity. JAMA Otolaryngol Head Neck Surg. 2013;139(12):1285-90.

96. Larsen RG, Bowdino CS, Van Leeuwen BJ, LaGrange CA, Deibert CM. The positive effect of monetary incentive on urology resident research. Urology. 2020;146:43-8
97. Gordon MB, Osganian SK, Emans SJ, Lovejoy FH Jr. Gender differences in research grant applications for pediatric residents. Pediatrics. 2009;124(2):e355-61.

98. Burrows AM, Laupland KB. Comprehensiveness of distributed medical education systems: a regional population-based perspective. BMC Med Educ. 2021;21(1):42.

\section{Publisher's Note}

Springer Nature remains neutral with regard to jurisdictional claims in published maps and institutional affiliations.
Ready to submit your research? Choose BMC and benefit from:

- fast, convenient online submission

- thorough peer review by experienced researchers in your field

- rapid publication on acceptance

- support for research data, including large and complex data types

- gold Open Access which fosters wider collaboration and increased citations

- maximum visibility for your research: over $100 \mathrm{M}$ website views per year

At BMC, research is always in progress.

Learn more biomedcentral.com/submissions 